\title{
Hydroethanolic Allium sativum extract accelerates excision wound healing: evidence for roles of mast-cell infiltration and intracytoplasmic carbohydrate ratio
}

\author{
Mohammad Reza Farahpour ${ }^{1, *}$, Saeed Hesaraki², Darab Faraji ${ }^{3}$, Rasoul Zeinalpour ${ }^{3}$, \\ Mohammad Aghaei ${ }^{4}$
}

\begin{abstract}
${ }^{1}$ Department of Clinical Sciences, Faculty of Veterinary Medicine, Urmia Branch, Islamic Azad University, Urmia, Iran, ${ }^{2}$ Department of Pathology, Faculty of Veterinary Medicine, Science and Research Branch, Islamic Azad University, Tehran, Iran, ${ }^{3}$ Department of Clinical Sciences, Faculty of Veterinary Medicine, Urmia Branch, Islamic Azad University, Urmia, Iran,

${ }^{4}$ Young Researchers and Elites club, Science and Research Branch,Islamic Azad University, Tehran, Iran
\end{abstract}

\begin{abstract}
The present study was designed to evaluate the in vivo effect of Allium sativum (garlic) hydroalcoholic extract on wound healing in rats. For this purpose, 72 mature Wistar rats were divided into four groups $(\mathrm{n}=18 / \mathrm{each})$ to receive no treatment, placebo, Cicalfate $\AA$, or $2 \%$ Allium sativum (AS) extract, administered topically to the wound area, for 21 days. Following the experimental period, tissue samples were dissected out and underwent to histopathological analyses. Fibroblasts, fibrocytes, mast cells, intra-cytoplasmic carbohydrate ratio, neovascularization, collagen deposition, and re-epithelialization were analyzed in all groups. Animals in the treated groups showed significant enhancement in fibroblast, fibrocyte, and mast-cell distribution. Significantly higher neovascularization was observed on day 3 after wound induction in AS-treated animals versus those in the placebo, Cicalfate, and untreated groups $(\mathrm{P}<0.05)$. A dose-dependent, significantly higher intra-cytoplasmic carbohydrate storage was observed in treated animals. Our data show that AS promotes wound healing due to its preliminary impact on mast-cell distribution, which enhanced collagen synthesis and upregulated angiogenesis, and shortened the healing process by enhancing the intra-cytoplasmic carbohydrate ratio.
\end{abstract}

Uniterms: Allium sativum/effects/rats. Allium sativum/wound healing/study. Allium sativum/mast cells. Allium sativum/angiogenesis. Intra-cytoplasmic carbohydrate.

\section{INTRODUCTION}

From a clinical point of view, wounds are an important challenge. Microbial interference, the presence of diseases such as diabetes, and inappropriate monitoring can lead to severe impairments of the healing process. This process consists of three different phases: inflammation, proliferation, and remodeling (Hemmati, Mohammadian, 2000; Bairy, Rao, 2001). Several synthetic drugs can be administered to speed or shorten the healing period. In addition, natural substances such as Gingko biloba, quince seed mucilage, yarrow, and licorice can be used to improve the healing process and promote the proliferation

\footnotetext{
*Correspondence: M.-R. Farahpour. Department of Clinical Sciences. Faculty of Veterinary Medicine. Urmia Branch, Islamic Azad University. Urmia - Iran. E-mail:mrf78s@gmail.com
}

and remodeling stages (Hemmati, Mohammadian, 2000; Bairy, Rao, 2001; Arzi, Hemmati, Amin, 2003).

Cicalfate (Crème réparatrice Avène; Laboratories dermatologiques Avène, France), a commercially available synthetic cream, is widely used to treat cuts, burns, diaper rash, and other forms of skin discomfort. It is mainly administered to accelerate the wound healing and recovery processes. This cream contains: Water (Agua), Caprylic/ Capric Triglycerides, Mineral Oil (Paraffinum Liquidum), Glycerin, Hydrogenated Vegetable Oil, Zinc Oxide, Propylene Glycol, Polyglyceryl 2 Sesquiisostearate, PEG 22 Dodecyl Glycol Copolymer, Aluminum Sucrose Octasulfate, Aluminum Stearate, Beeswax (Cera Alba), Copper Sulfate, Magnesium Stearate, Magnesium Sulfate, Microcrystalline Wax (Cera Microcristallina), Zinc Sulfate.

Allium sativum L. (Amaryllidaceae), a member of the lily family, grows widely in southwest and central 
Asia. In North America, A. sativum is known as wild garlic or crow garlic (Ejaz et al., 2009). According to most previous clinical reports, it exerts massive antioxidant, antiplatelet, and antifibrinolytic effects, and has impacts on the microcirculation (Sundaresan, Subramanian 2003; MacDonald, Marchand, Langler 2004). A. sativum contains high levels of alliin, allyl cysteine, allyl disulfide, and allicin, which are known as powerful antioxidant agents (Chung, 2006). In this regard, previous studies illustrated that elevated antioxidant agents in the wound area, accelerate the healing process (Rasik, Shukla, 2000; Farahpour et al., 1015). However, beside antioxidant agents, anti-inflammatory chemicals also play important roles in accelerating the healing process. In fact, controlling inflammatory reaction during the healing process results in rapid onset of the proliferative stage and well-formed cellularity (Hemmati, Mohammadian, 2000; Rasik, Shukla, 2000). Large groups of cells, including neutrophils, macrophages, and lymphocytes, are involved in the wound healing process, in which they help eliminate contamination by microorganisms and clear cellular debris (Guo, Dipietro, 2010). According to Shin et al. (2013), A. sativum has massive anti-inflammatory effects.

Carbohydrates are known as the main sources of the energy used in collagen synthesis. Thus, these compounds play an essential role in shortening the healing process by upregulating collagen synthesis during the maturation stage (Wolfe et al., 1983).

Within this context, the present study was conducted to evaluate the effect of topical administration of a hydroalcoholic extract of $A$. sativum on the wound healing process. For this purpose, all three stages of the wound healing process - inflammation, proliferation, and remodeling - were investigated in a rat model. Furthermore, the presumed accelerating properties of $A$. sativum on healing were compared with those of Cicalfate, a commercially available cream.

\section{METHODS}

\section{Plant material and extract preparation}

Allium sativum cloves were hand-collected in the central district of the Hamadan region, Iran (latitude $34.80^{\prime}$ ', longitude 48.51'), in July. The species identification was authenticated by the Department of Botany Sciences, Agriculture and Natural Resources Research Center, Hamadan, Iran. Cloves were separated, sliced by hand, and approximately $500 \mathrm{~g}$ of fresh plant material was left to dry naturally in the shade on laboratory benches, at room temperature $\left(23-24{ }^{\circ} \mathrm{C}\right)$, for 6 days until crisp. The dry material was powdered in an electric blender, and 50 $\mathrm{g}$ of the resulting powder was suspended in $1000 \mathrm{ml}$ of hydroethanolic solution for $96 \mathrm{~h}$ at room temperature. The mixture was filtered through a fine muslin cloth followed by filter paper (Whatman No 1). The filtrate was then shaken at room temperature for $24 \mathrm{~h}$. The resulting extract was oven-dried at $40^{\circ} \mathrm{C}$ for $24 \mathrm{~h}$, yielding $12 \mathrm{~g}$ of dry extract. The extracts were stored at $-20^{\circ} \mathrm{C}$ until use in the experiment (Abad, Nouri, Tavakkoli, 2011; Prichoa, Roman, Manfredini, 2011).

\section{Total phenol and flavonoid content}

Total phenolic constituents of sample extracts were determined by a modification of the methods described by Saeed, Khan, Shabbir (2012) using Folin-Ciocalteu reagent and gallic acid (range, $0-1000 \mathrm{mg} / \mathrm{L}$ ) as standard phenolic compound. The aluminum chloride method was used for determination of the total flavonoid content of the extracts, expressed as mg of quercetin equivalents per gram of dried extract (Saeed, Khan, Shabbir, 2012).

\section{Experimental animals and study design}

Healthy white male Wistar rats weighing approximately $200 \mathrm{~g}$ and aged 9 weeks were used in the present study. Two weeks before and throughout the experimental period, the animals were housed in individual plastic cages $(50 \times 40 \times 20 \mathrm{~cm})$ with an ambient temperature of $23 \pm 3{ }^{\circ} \mathrm{C}$, stable air humidity, and a natural day/night cycle. The animals were handled on a daily basis for 2 weeks prior to the study in order to acclimate them to the testing area and experiments, with a view to mitigating anxiety-related testing inaccuracies. The rats had free access to standard rodent laboratory food and tap water. All animal procedures were carried out based on the guidelines of the Ethics Committee of the International Association for the Study of Pain (Zimmermann, 1983). The University Research Council approved all experiments with approval number A1393.

\section{Circular excision wound model and cream formulation}

Animals in each group were anesthetized by intraperitoneal administration of ketamine $5 \%, 70 \mathrm{mg} /$ $\mathrm{kg}$ (Ketaset 5\%, Alfasan, Woerden, The Netherlands) and xylazine hydrochloride $2 \%, 5 \mathrm{mg} / \mathrm{kg}$ (Rompun $2 \%$, Bayer, Leverkusen, Germany). The fur was prepared aseptically and a predetermined area was marked on the back of each animal. Each rat was secured to the operating table in ventral recumbency. Then, a full-thickness 
circular surgical wound, $314 \mathrm{~mm}^{2}$ in diameter, was made on the anterior-dorsal aspect of each rat, using a scalpel and surgical scissors (Farahpour et al., 2015) Wound contraction percentage and wound closure time were used to assess the wound-healing properties. All 72 rats were then randomly labeled with a nontoxic dye and divided into four groups. Two groups served as controls: Group 1, which did not receive any chemical/ointment treatment; Group 2 (Placebo), in which animals were treated with yellow soft paraffin (PARS DARUO. Ltd., Tehran, Iran); Group 3, treated with Cicalfate cream; and Group 4, treated with a cream consisting of $2 \%$ hydroethanolic extract of $A$. sativum cloves in yellow soft paraffin. The creams were applied topically to the wound area once a day, from the day of operation until postoperative day 21 . All rats were monitored for wound discharge and other evidence of infection or abnormalities until complete epithelialization.

\section{Wound area measurement}

The wound area was measured by immediately placing a sheet of transparent paper over the wound and tracing its perimeter; the area of this impression was calculated using graph paper. At the beginning of the experiments and on postoperative days $4,8,12,16$, and 20 , wound healing percentage was calculated by the Walker formula (Walker, Mason Jr., 1968) as follows: percent wound size $=$ wound area on day X / wound area on day zero $\times 100$; wound healing percentage $=100$ - percent wound size.

\section{Histopathological study}

On days 7, 14, and 21 after wound induction, crosssectional full-thickness specimens of the wound tissue were dissected out and different phases of the wound healing process were investigated in these samples. Specimens were fixed in $10 \%$ buffered formalin, processed, paraffinembedded, cut with a rotary microtome (5- $\mu \mathrm{m}$ slices), and stained for different purposes, as described below (Mashreghi et al., 2013; Süntar et al., 2012; Prichoa, Roman, Manfredini, 2011; Farahpour et al., 2015).

\section{Estimation of intracytoplasmic carbohydrate content}

To evaluate the intracytoplasmic carbohydrate ratio, the periodic acid schiff (PAS) staining technique (AYANDEH (s) Science Co. Kit, Iran) was employed (Farahpour et al., 2015). In brief, the sections were deparaffinized, hydrated, and oxidized in $5 \%$ periodic acid solution for $5 \mathrm{~min}$. After rinsing in distilled water, the slides were placed in Schiff reagent for $15 \mathrm{~min}$ before being washed with lukewarm water. After 5 min, the counter-slides were stained with Meyer's hematoxylin. Tissue samples were analyzed under a light microscope (Olympus CX41) coupled to a Camera ms Digital Image Analysis System. Cells with red-stained spots in the cytoplasm were analyzed per $1 \mathrm{~mm}^{2}$ of tissue in the ImagePro Insight software suite, and staining graded as negative $(-)$, mild $(+)$, moderate $(++)$, and marked $(+++)$ (Farahpour et al., 2015).

\section{Distribution of mast cells}

To analyze the distribution of mast cells, toluidineblue staining was performed based on the Sheehan method (Sheehan, Hrapchak, 1980). The slides were deparaffinized, hydrated in distilled water, stained in toluidine-blue working solution for $3 \mathrm{~min}$, and rinsed in three changes of distilled water. Slides were then dehydrated quickly through $95 \%$ and absolute alcohols. Following dehydration, the slides were cleared and coverslipped. The mean distribution of mast cells was estimated in $1 \mathrm{~mm}^{2}$ of connective tissue and recorded.

\section{Assessment of collagen fibers}

Collagen-fiber synthesis was estimated with Masson's trichrome technique (AYANDEH (s) Science Co. kit, Iran). In brief, sections were hydrated in distilled water and re-fixed in Bouin's solution for 1 hour at $56^{\circ} \mathrm{C}$. After rinsing in distilled water, the slides were stained with a working solution of Weigert's iron hematoxylin for 10 min. Then, the slides were rinsed in distilled water, stained in Biebrich's scarlet-acid fuchsin solution for 10-15 min, and differentiated in phosphomolybdic-phosphotungstic acid solution for 10-15 min. the slides were then transferred directly (without rinsing) to an aniline blue solution, stained for 5-10 min, rinsed briefly in distilled water, and differentiated in $1 \%$ acetic acid solution for $2-5$ minutes. Following dehydration, the slides were cleared and cover-slipped. A 1-mm ${ }^{2}$ area of tissue was analyzed in Image-Pro Insight (version 6.00) and staining graded as mild $(+)$, mild to moderate $(++)$, moderate $(+++)$, or marked $(++++)$.

\section{Histomorphometric analyses and assessment of} connective tissue and immune-cell distribution

Epithelium thickness was compared on different days and between groups. The distribution of immune cells, fibroblasts, and fibrocytes was estimated in $1 \mathrm{~mm}^{2}$ of the tissue and compared between groups. Edema was analyzed in all groups and graded as negative (-), mild (+), mild to moderate $(++)$, moderate $(+++)$, or marked $(++++)$ (Farahpour et al., 2015). 
Alkaline phosphatase staining

Staining for alkaline phosphatase (ALP) was performed with a commercially available kit (Pajhohesh Asia, Iran). Briefly, the slides were rehydrated with 3 to 4 dips in absolute acetone, $80 \%$ acetone-water, and 50\% acetone-water solution, respectively; rinsed several times in distilled water; and incubated in incubating solution at $37^{\circ} \mathrm{C}$ for $40 \mathrm{~min}$. Following incubation, the slides were washed in water and incubated in cobalt nitrate for 5 min. Following a simple rinse in water, the slides were treated with yellow ammonium sulfide for $2 \mathrm{~min}$ and counterstained with hematoxylin solution.

\section{Statistical analyses}

Experimental results were reported as means \pm standard error (SEM) and standard deviation (SD). Statistical analyses were performed using PASW 18.0 (SPSS Inc., Chicago, IL, USA). Model assumptions were evaluated by examining the residuals plot. Results were analyzed using two-way ANOVA. Dunnett's test for pairwise comparisons was used to examine the effect of time and treatments. Statistical differences were considered significant when $P<0.05$ and $P<0.01$.

\section{RESULTS}

\section{Total phenol and flavonoid content}

Biochemical analyses revealed a total phenol content of $24.2 \mathrm{mg} / 100 \mathrm{~g}$ dried weight extract and a total flavonoid content of $35.9 \mathrm{mg} / 100 \mathrm{~g}$ dried weight extract.

\section{Wound contraction developed in Allium sativum- treated animals}

Administration of different doses of $A$. sativum extract in this excision wound model significantly $(\mathrm{P}<0.05)$ increased the wound contraction rate compared to the control (sham), placebo-treated, and Cicalfate-treated animals. In A. sativum-treated animals, wound closure was achieved on postoperative day 8 , while no such healing occurred in the other groups. Comparison of the contraction rate between groups showed that, at day $8, A$. sativum-treated animals exhibited significantly a $(\mathrm{P}<0.05)$ higher contraction rate $(116.33 \pm 12.71)$ in comparison to the Cicalfate $(144.03 \pm 8.47)$ and placebo $(191.8 \pm 22.97)$ groups, which, in turn, exhibited significantly $(\mathrm{P}<0.05)$ higher rates than that of the control-sham group (209.43 $\pm 14.24)$. Detailed wound contraction data are presented in Table I.

\section{Allium sativum enhanced intra-cytoplasmic carbohydrate storage both in epithelial and in connective cells}

Histochemical PAS staining showed that $A$. sativum upregulated intracytoplasmic carbohydrate storage. Accordingly, animals in the A. sativum-treated groups exhibited a marked reaction to PAS staining in connective cells (especially fibroblasts and fibrocytes) versus placebo and Cicalfate-treated animals. Light microscopy analyses for carbohydrate foci in epithelial cells in all groups showed that animals in the AS-treated group exhibited increasing reaction to PAS staining (Figure 1). However, animals in the placebo and Cicalfate-treated groups showed the same phenomenon on day 21 after wound induction. Data for PAS staining are shown in Table II.

\section{Mast-cell distribution was elevated in Allium sativum- treated animals}

Staining for mast cells showed that, in A. sativumtreated animals, mast-cell infiltration was significantly $(\mathrm{P}<0.05)$ higher than in placebo-treated, Cicalfatetreated, and control-sham animals in all time points after

TABLE I - Effects of the topical hydroethanolic Allium sativum cloves extract (AS) on circular excision wound contraction area $\left(\mathrm{mm}^{2}\right)$ in rat

\begin{tabular}{|c|c|c|c|c|c|}
\hline \multirow{2}{*}{ Groups } & \multicolumn{5}{|c|}{ Wound area $\left(\mathrm{mm}^{2}\right) \pm$ S.D. } \\
\hline & 4 & 8 & 12 & 16 & 20 \\
\hline Control & $\begin{array}{c}251.04 \pm 12.16 \\
(20.04 \%)\end{array}$ & $\begin{array}{c}209.43 \pm 14.24 \\
(33.3 \%)^{c}\end{array}$ & $\begin{array}{c}78.97 \pm 13.79 \\
(74.85 \%)^{\mathrm{c}}\end{array}$ & $\begin{array}{c}26.69 \pm 5.17 \\
(91.48 \%)^{\mathrm{c}}\end{array}$ & $\begin{array}{l}6.12 \pm 4.59 \\
(98.05 \%)^{\mathrm{c}}\end{array}$ \\
\hline Placebo & $\begin{array}{c}245.54 \pm 16.26 \\
(21.8 \%)\end{array}$ & $\begin{array}{c}191.8 \pm 22.97 \\
(42.1 \%)^{\mathrm{c}} \\
\end{array}$ & $\begin{array}{c}51.96 \pm 13.6 \\
(83.45 \%)^{\mathrm{b}}\end{array}$ & $\begin{array}{c}23.86 \pm 7.07 \\
(92.38 \%)^{\mathrm{c}}\end{array}$ & $\begin{array}{l}4.39 \pm 1.8 \\
(98.6 \%)^{\mathrm{bc}}\end{array}$ \\
\hline Cicalfate & $\begin{array}{c}262.66 \pm 7.95 \\
(16.34 \%)\end{array}$ & $\begin{array}{c}144.03 \pm 8.47 \\
(52.48 \%)^{\mathrm{b}}\end{array}$ & $\begin{array}{c}26.22 \pm 2.45 \\
(91.65 \%)^{\mathrm{a}}\end{array}$ & $\begin{array}{c}14.79 \pm 10.01 \\
(95.27 \%)^{\mathrm{b}}\end{array}$ & $\begin{array}{l}1.72 \pm 1.16 \\
(99.45 \%)^{\mathrm{ab}}\end{array}$ \\
\hline AS-treated & $\begin{array}{c}262.5 \pm 8.16 \\
(16.38 \%)\end{array}$ & $\begin{array}{c}116.33 \pm 12.71 \\
(62.94 \%)^{\mathrm{a}}\end{array}$ & $\begin{array}{c}26.22 \pm 3.31 \\
(91.65 \%)^{\mathrm{a}}\end{array}$ & $\begin{array}{c}8 \pm 2.24 \\
(96.44 \%)^{\mathrm{a}}\end{array}$ & $\begin{array}{l}0.0 \pm 0.0 \\
(100 \%)^{\mathrm{a}}\end{array}$ \\
\hline
\end{tabular}

Data are presented as the mean $\pm \mathrm{SD}$. There are significant differences between groups with different codes in a column (superscript letters $\mathrm{a}, \mathrm{b}$ and $\mathrm{c} ; \mathrm{P}<0.05)$. 


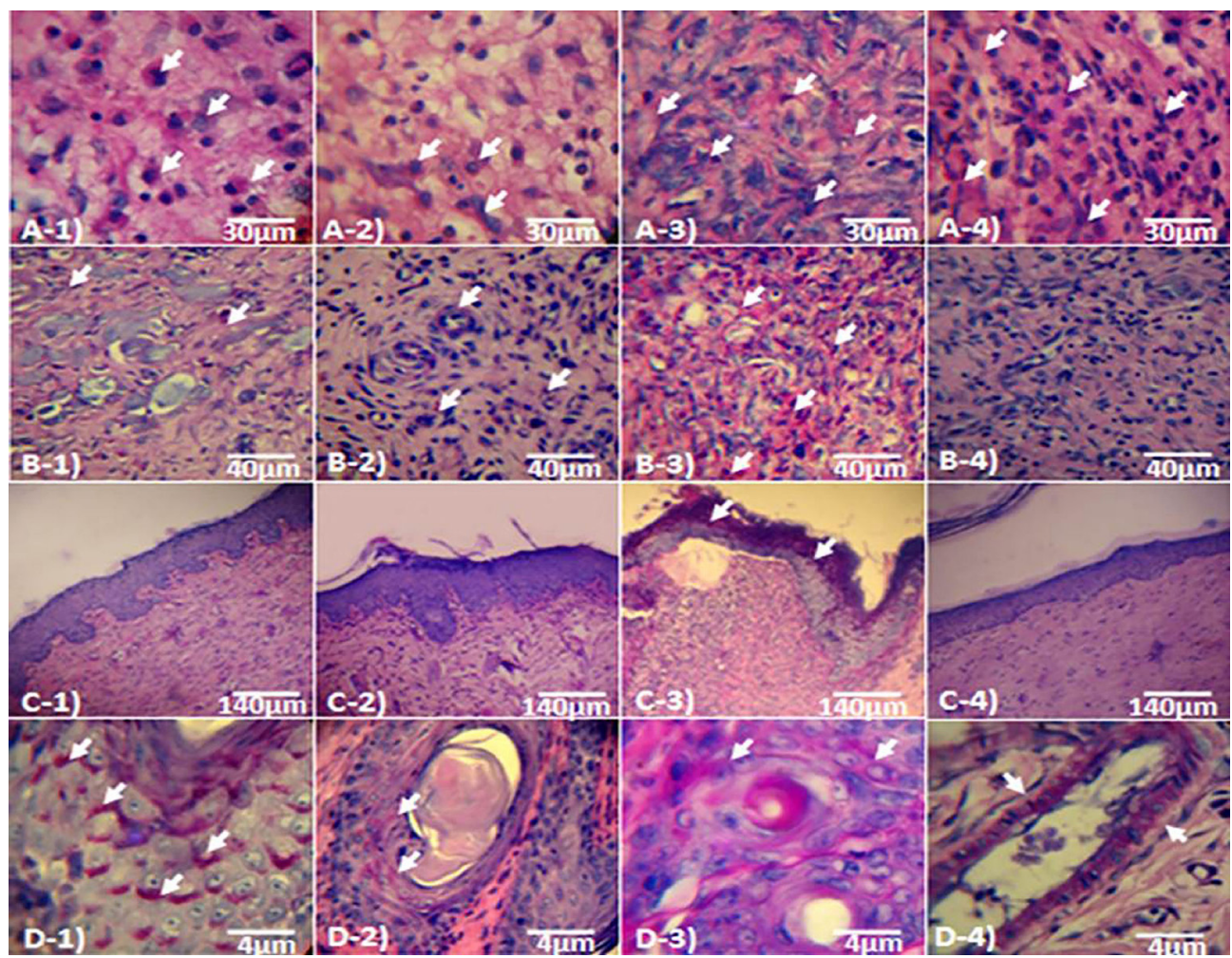

FIGURE 1 - (A) cross section from dermis on day 7 after wound induction: (A-1) control, (A-2) Placebo-treated (A-3) Cicalfatetreated and (A-4) Allium sativum-treated groups; note increased intracytoplasmic carbohydrate accumulation (arrows) in AS-treated animals. (B) Cross section from dermis on day 12 after wound induction: (B-1) control, (B-2) Placebo-treated (B-3) Cicalfate-treated and (B-4) Allium sativum-treated groups. Mean distribution of the PAS positive cells are significantly higher in Allium sativumtreated dermis versus in non-treated, placebo and Cicalfate-administrated group. (C) Cross section from epidermis and dermis on day 21: (C-1) control, (C-2) Placebo, (C-3) Cicalfate-treated and (C-4) Allium sativum-treated groups: the Allium sativum-treated animals exhibited increased carbohydrate ratio in epidermal cells after 21 days. Higher magnification for carbohydrate accumulation in stratum spinosum (D-1), high carbohydrate storage in meissner corpuscle's peripheral cells (D-2), intensive PAS reaction around newly generated hair sprouts (D-3) and high carbohydrate storage in endothelial cells (B-4), (A, B: 600×; C: 400×; D: 800×).

TABLE II - Effects of topical hydroethanolic Allium sativum cloves extract (AS) on tissue reaction scores for Masson trichrome, $P A S$ and $A L P$ staining

\begin{tabular}{lccccc}
\hline Groups & Edema score & Collagen score & $\begin{array}{c}\text { Epidermis } \\
\text { thickness }\end{array}$ & PAS & ALP \\
\hline Control-sham (Day 7) & ++++ & - & - & - & ++++ \\
Placebo (Day 7) & +++ & - & - & - & ++++ \\
Cicalfate- treated (Day 7) & ++ & ++ & $10.24 \pm 1.06$ & + & ++ \\
AS-treated (day7) & + & ++ & - & + & ++ \\
Control-sham (Day 14) & ++ & + & - & ++ & ++ \\
Placebo (Day 14) & ++ & + & - & ++ & ++ \\
Cicalfate-treated (Day 14) & + & ++ & $36.61 \pm 5.33^{\mathrm{a}}$ & +++ & - \\
AS-treated (day14) & - & +++ & $68.30 \pm 4.63^{\mathrm{b}}$ & ++++ & ++ \\
Control-sham (Day 21) & ++ & + & $10.27 \pm 3.39^{\mathrm{a}}$ & +++ & ++ \\
Placebo (Day 21) & + & ++ & $16.41 \pm 5.73^{\mathrm{b}}$ & +++ & + \\
Cicalfate- treated (Day 21) & - & +++ & $180.00 \pm 9.34^{\mathrm{c}}$ & +++ & - \\
AS-treated (day21) & - & ++++ & $270.40 \pm 6.80^{\mathrm{d}}$ & ++++ & + \\
\hline
\end{tabular}

Note: ++++: Intensive; +++: Mild; ++: Mild to moderate; +: Faint; -: negative.

a,b,c are presented significant differences $(\mathrm{P}<0.05)$ between marked data in the same column, in each day. 
wound induction. Generally, the distribution of mast cells increased at 7 day after wound induction, but this phenomenon was significantly more pronounced in the A. sativum-treated group (Figure 2 and 3 ).

\section{Collagen deposition, connective tissue cells, re-} epithelialization, and edema

Animals in the A. sativum group exhibited wellformed granulation tissue on day 7 after wound induction. These animals also showed significantly $(\mathrm{P}<0.05)$ less immune-cell infiltration compared to control-sham animals and other treated groups on day 7 (Figure 4). Accordingly, animals in the A. sativum group exhibited a remarkable inhibition of inflammation, as well as significantly $(\mathrm{P}<0.05)$ increased fibroblast and fibrocyte distribution (Figure 5A and B). Considerably higher collagen deposition, especially in the deeper dermis, was also seen in the A. sativum group. Interestingly, animals in this group showed re-epithelialization on day 7 after wound induction. Meanwhile, animals in the control-sham group exhibited only faint epithelialization on day 14

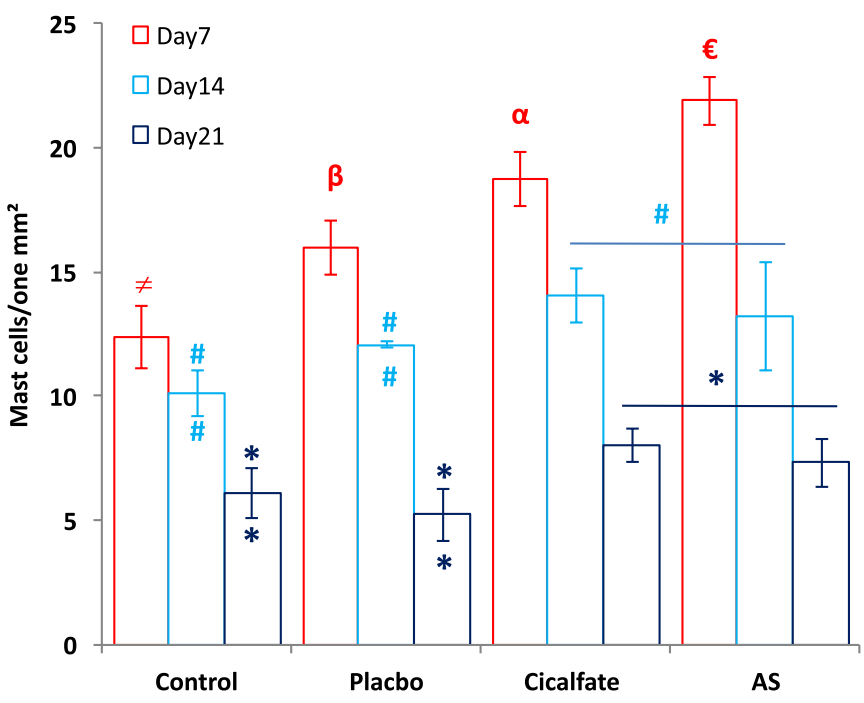

FIGURE 2 - Mean distribution of mast cells in one mm2 of the wound area on days 7,14 and 21 after wound induction. All data are presented in Mean $\pm \mathrm{SD},\left({ }^{\#}\right.$ versus ${ }^{\# \#}$ : $\left.\mathrm{P}<0.01\right)$; ( * versus $* *: \mathrm{P}<0.05) ;(\neq, \boldsymbol{\beta}, \boldsymbol{\alpha}, \epsilon: \mathrm{P}<0.05)$. Note: Control: non-treated group, Placebo: Placebo-treated, Cicalfate: Cicalfate-treated and AS: Allium sativum-treated.
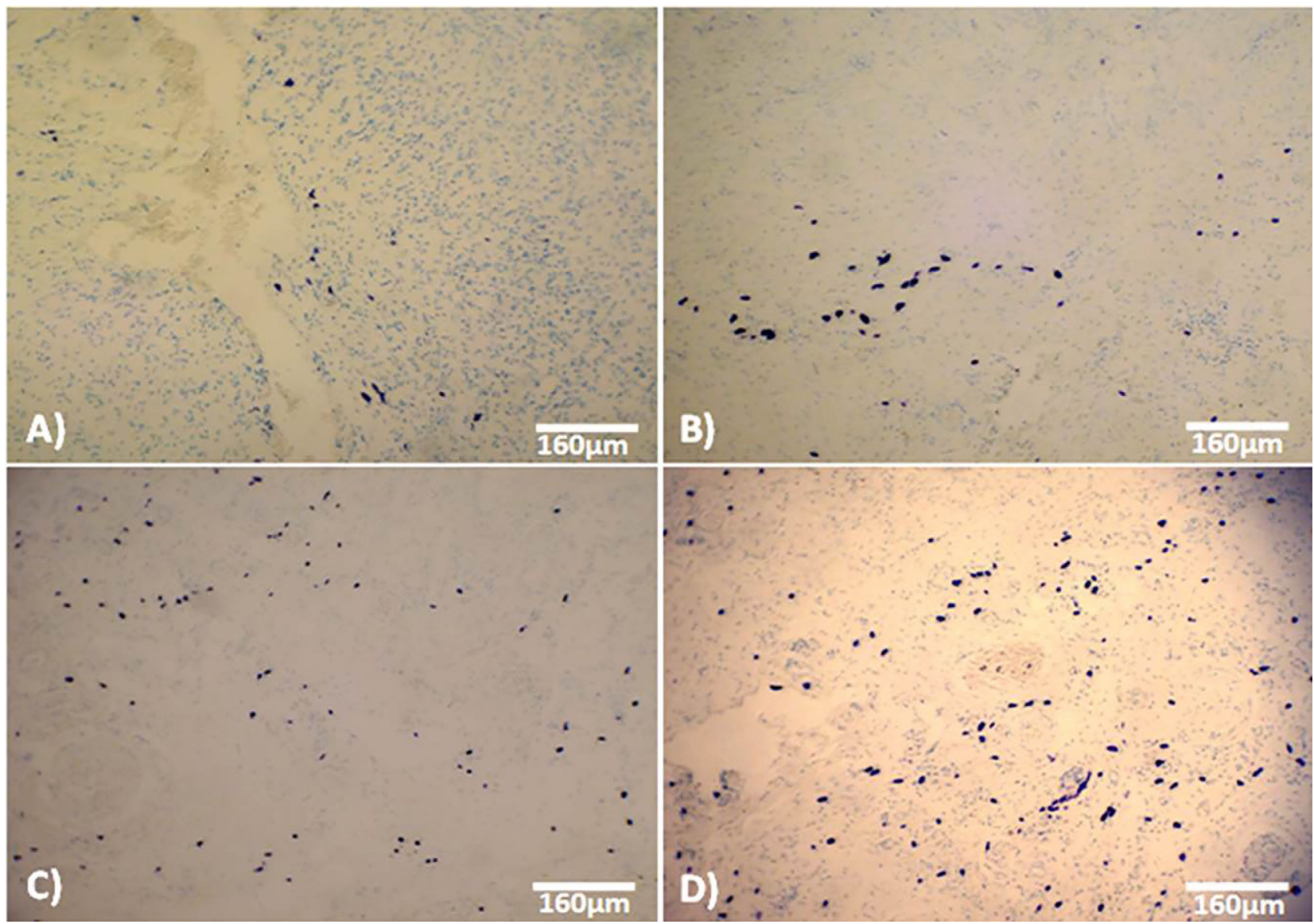

FIGURE 3 - Cross section from dermis on day 7 after wound induction: (A) control, (B) Placebo-treated, (C) Cicalfate-administrated and (D) AS-treated groups. Note increased mast cells distribution in Allium sativum-treated dermis (blue stained cells). Toluidineblue staining, $(400 \times)$. 
after wound induction. However, on days 14 and 21, the newly generated epithelium in A. sativum-treated animals was significantly $(\mathrm{P}<0.05)$ thicker than in control-sham animals. Comparison of edema scores between groups showed that administration of $A$. sativum extract was able to completely prevent edema on day 14 after wound induction (Table II).

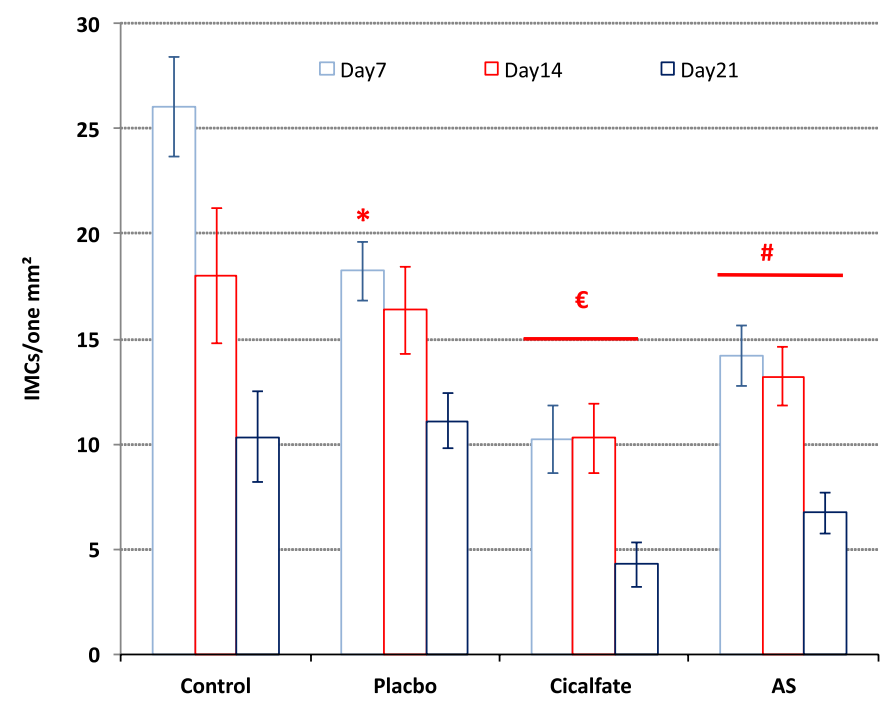

FIGURE 4 - Mean distribution of immune cells (IMNs) in one $\mathrm{mm} 2$ of the wound area on days 7,14 and 21 after wound induction. All data are presented in Mean $\pm \mathrm{SD} .{ }^{\epsilon}$ and $^{\#}$ are representing the significant differences between marked groups with each other and with placebo-treated group. *is presenting significant difference between placebo-treated group versus control group on day 7. Note: Control: non-treated group, Placebo: Placebo-treated, Cicalfate: Cicalfate-treated and AS: Allium sativum-treated.

\section{Angiogenesis enhanced in Allium sativum-treated animals}

On day 7 after wound induction, A. sativumtreated animals showed a significant $(\mathrm{P}<0.05)$ increase in neovascularization. In contrast, significantly $(\mathrm{P}<0.05)$ lower angiogenesis was demonstrated in Cicalfate-treated animals 7 days after wound induction. Comparison of angiogenesis between all groups on different days after wound induction showed that $A$. sativum extract significantly $(\mathrm{P}<0.05)$ enhanced vascular distribution on all days versus no treatment, placebo, or Cicalfate (Figure 6).

\section{ALP activity decreased in Allium sativum-treated animals}

Histochemical staining for the inflammation marker ALP was performed on days 7, 14, and 21 after wound
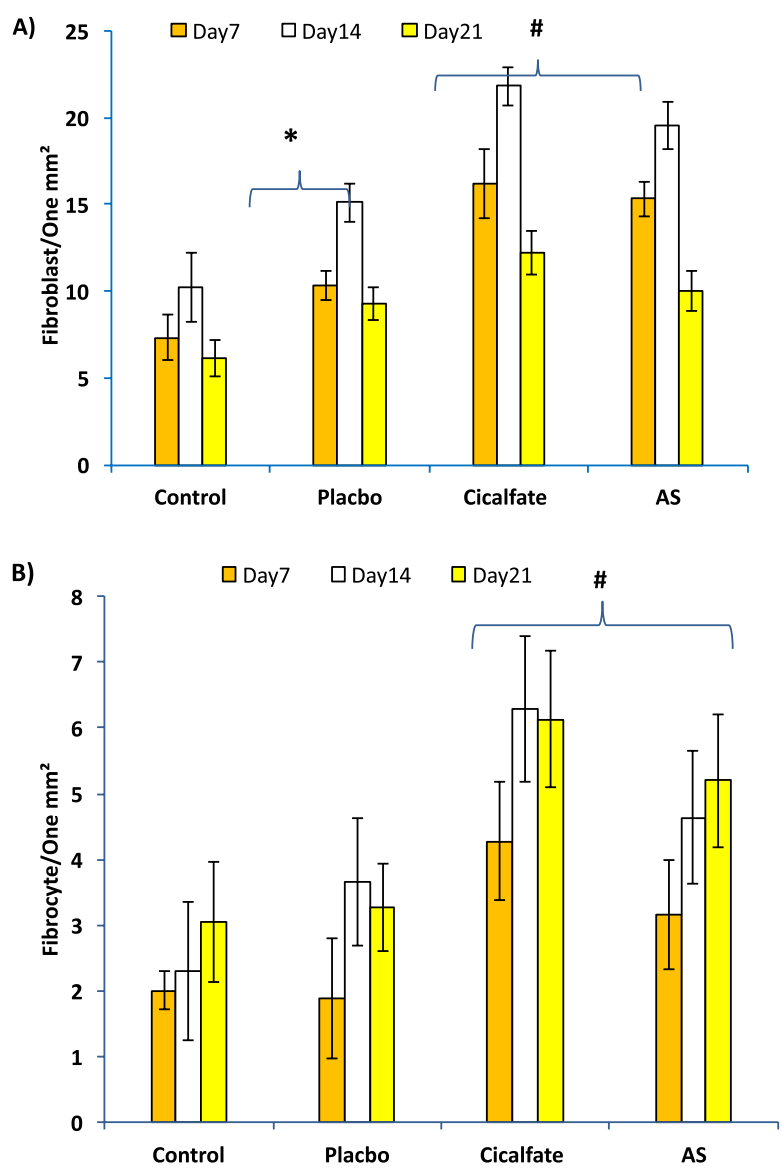

FIGURE 5 - Mean distribution of fibroblasts (A) and fibrocytes (B) in one $\mathrm{mm} 2$ of the wound area on days 7, 14 and 21 after wound induction. All data are presented in Mean \pm SD. *and ${ }^{\#}$ are representing the significant differences between marked groups. Note: Control: non-treated group, Placebo: Placebo-treated, Cicalfate: Cicalfate-treated and AS: Allium sativum-treated.

induction. Animals in the A. sativum-treated group showed a significant reduction in ALP activity on day 7 versus control-sham, placebo, and Cicalfate-treated animals. Animals in the Cicalfate-treated group also showed a reduction in ALP activity on day 7; however, activity was still higher than in the $A$. sativum extract group. In the $A$. sativum group, ALP activity was also reduced on day 14 and absent altogether on day 21 (Figure 7). Conversely, on day 14 after wound induction, animals in the control, placebo, and Cicalfate-treated groups showed marked, moderate, and mild to moderate ALP reactions respectively (Table II).

\section{DISCUSSION}

In the present study, we demonstrated the promoting effect of an A. sativum extract on wound healing process. Moreover, A. sativum exerted impacts comparable to those of a widely used, commercially available ointment 


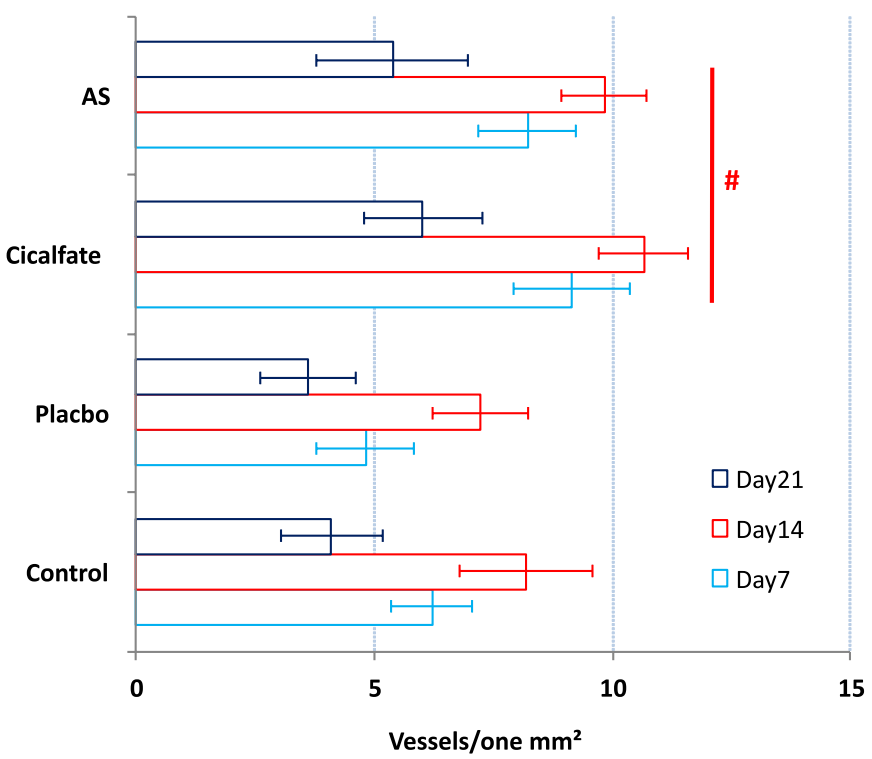

FIGURE 6 - Mean distribution of vessels in one $\mathrm{mm} 2$ of the wound area on days 7, 14 and 21 after wound induction. All data are presented in Mean \pm SD. ${ }^{*}$ is representing the significant differences between AS-and-cicalafte-treated groups with placebo-treated and control group. Note: Control: non-treated group, Placebo: Placebo-treated, Cicalfate: Cicalfate-treated and AS: Allium sativum-treated.
(Cicalfate) at different stages of the healing process. By upregulating the intracytoplasmic carbohydrate ratio, shortening the inflammatory stage of the healing process, enhancing angiogenesis, inducing the proliferative stage, and, finally, accelerating collagen synthesis, $A$. sativum decreased the essential period for healing.

It has been reported that wound healing is a dynamic process that largely depends on rapid reforming of the damaged tissue into a normal condition. In this regard, downregulation of inflammation associated with induced angiogenesis, even in preliminary stages, promotes the proliferative machinery, including the physiologic and/ or compensatory functions of fibroblasts and fibrocytes (Martin, 1997; Kumar, Katoch, Sharma, 2007). Our histological and clinical observations showed that administration of $A$. sativum extract resulted in a rapid shutdown of the inflammatory stage of healing (marked by decreased immune cell (IMC) infiltration and ALP activity) and increased the wound contraction ratio. Thus, as a preliminary finding, we can suggest that $A$. sativum accelerated the healing process by promoting dynamic healing.

Carbohydrates, especially glycogen, are known to act as the storage medium of the epidermal and
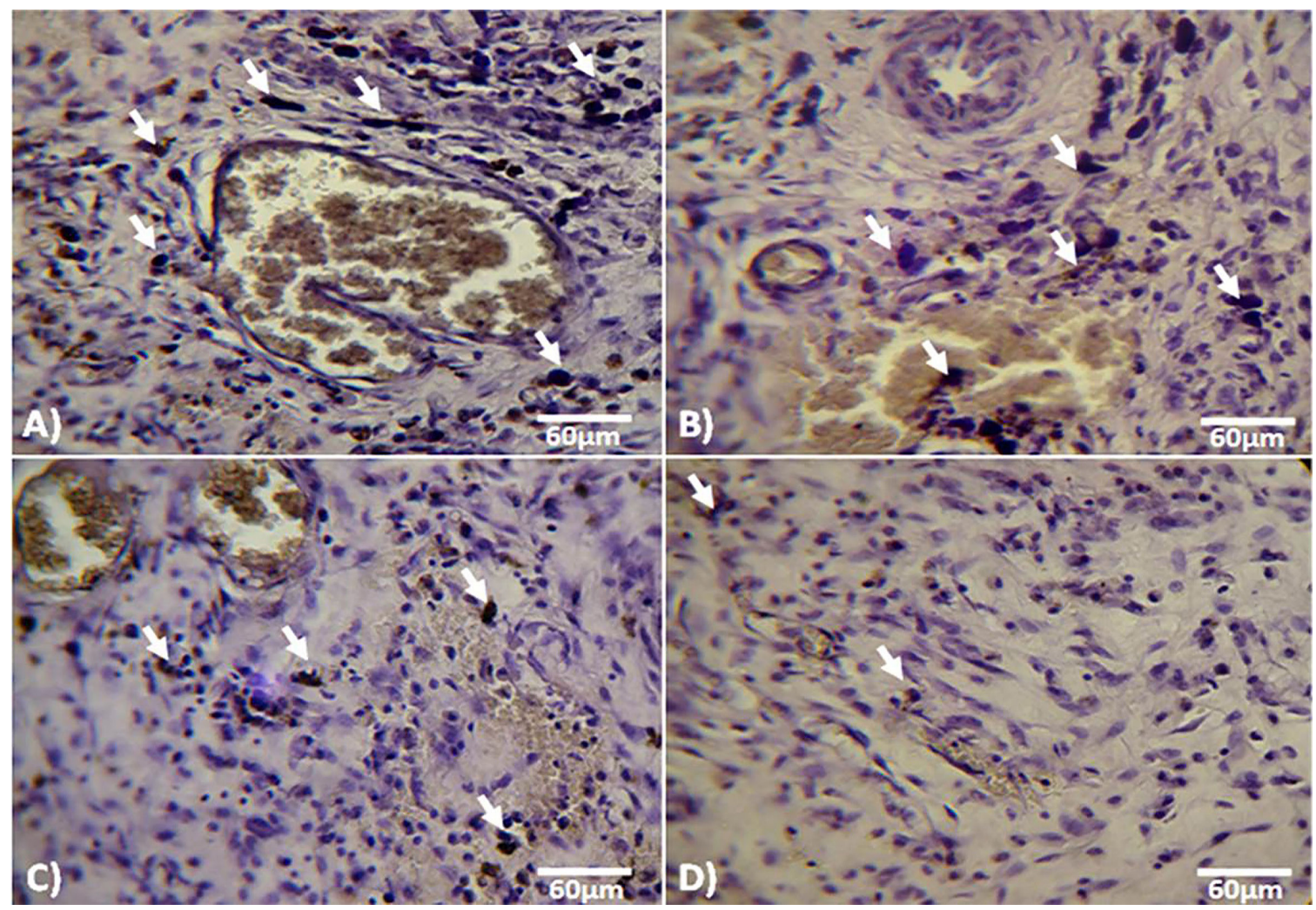

FIGURE 7 - Cross section from dermis on day 7 after wound induction: (A) control, (B) Placebo-treated, (C) Cicalfate-administrated and (D) AS-treated groups. Note inhibited ALP synthesis (arrows) in Allium sativum-treated animals in comparison with nontreated, placebo-and-Cicalfate-treated animals. Alkaline-phosphatase staining, $(800 \times)$. 
dermal skin cells in rats, human, and many other animal species (Wolfe et al., 1983; Demling, Leslie, 2003). Under different injury conditions, albeit depending on the depth and environment of the damaged area, the intracytoplasmic carbohydrate ratio differs across cells types (Mancini, 1984; Wolfe et al., 1983; Demling, Leslie, 2003). Moreover, carbohydrates are essential preliminary compounds used in synthesis of hyaluronic acid, proteoglycan, and glycosaminoglycans, and are known to be stored at high levels in injured skin epithelium (especially in the stratum spinosum) (Toole, Wight, Tammi, 2002; Turley, Noble, Bourguignon, 2002). In the present study, PAS staining for carbohydrates revealed that $A$. sativum-treated animals had significantly more frequent and stronger PAS-positive reactions compared to the other groups. Moreover, the stratum spinosum of the epidermis in A. sativum-treated animals exhibited remarkably higher intracytoplasmic carbohydrate storage. Therefore, we can hypothesize that topical treatment with A. sativum extract increased the carbohydrate ratio in dermal and epidermal cells, thus promoting the healing process by supporting these cells' energy requirements and providing the preliminary substrate needed for synthesis of structural compounds.

The wound healing process largely depends on homeostasis of three different stages. The inflammatory phase is considered a key step for clearing cellular debris from the injured tissue, as well as an essential response to microbial infection (Rao, Brown, 2008; Theoharides et al., 2012). However, it is crucial that the inflammation phase be brief. Indeed, rapid onset of cellular proliferation and differentiation is necessary for shortening the healing process (Rao, Brown, 2008). In the present study, $A$. sativum administration resulted in decreased IMCs infiltration and reduced ALP activity on day 7. These alterations were not observed in the control-sham and placebo-treated groups. On the other hand, administration of $A$. sativum extract enhanced fibroblast and fibrocyte proliferation, as well as collagen deposition. Therefore, it would be logical to conclude that $A$. sativum extract inhibited the inflammatory stage and promoted the proliferative stage.

According to previous reports, antioxidant agents are essential for synthesis of collagens, inhibiting inflammation and angiogenesis (Ambiga et al., 2007; Lodhi, Singhai, 2013). In this regard, our biochemical analyses showed that $A$. sativum extract exerted significant, strong antioxidant and anti-inflammatory effects. On the other hand, the distribution of mast cells (especially activated mast cells) enhances the angiogenesis ratio and indirectly inhibits the inflammatory stage of healing.
The role of mast cells in enhancing cellular proliferation during wound healing has been reported previously (Rao, Brown, 2008; Theoharides et al., 2012). Mast cells are known to secrete vascular growth factor (VGF), which stimulates endothelial cell proliferation; this, in turn, has been shown to upregulate neovascularization during the healing process (Younan et al., 2011). Our histological analyses showed that animals in the A. sativum-treated group exhibited a significantly higher mast-cell and vascular distribution compared to animals in the Cicalfate, placebo, and control-sham groups. Thus, we can conclude that, in addition to modulating the pathways mentioned above, A. sativum upregulated mast-cell distribution, thus enhancing angiogenesis and the cellular proliferation ratio.

\section{CONCLUSIONS}

Our data showed that the high flavonoid and phenol content of $A$. sativum reduced the inflammation-induced degenerative impacts in a rat model of wound healing. Moreover, it accelerated the healing process significantly by reducing inflammatory reaction (as demonstrated by diminished IMCs and ALP activity), enhancing mast-cell distribution, elevating the intracytoplasmic carbohydrate ratio, and promoting angiogenesis.

\section{ACKNOWLEDGMENTS}

This work is the result of a research project and was supported by Urmia Branch, Islamic Azad University, Urmia, Iran (grant number: 51035920412002 ).

The authors wish to thank the laboratory section of the AYANDEH Science Company for pathological assessment.

\section{REFERENCES}

ABAD, A.N.A.; NOURI, M.H.K.; TAVAKKOLI, F. Effect of Salvia officinalis hydroalcoholic extract on vincristineinduced neuropathy in mice. Chin. J. Nat. Med., v.9, n.5, p.354-358, 2011.

AMBIGA, S.; NARAYANAN, R.; GOWI, D.; SUKUMAR, D.; MADHAVAN, S. Evaluation of wound healing activity of flavonoids from Ipomoea carnea jaqu. Anc. Sci. Life, v.26, p.47-51, 2007.

ARZI, A.; HEMMATI, A.A.; AMIN, M. Stimulation of wound healing by licorice in rabbit. Saudi Pharm. J., v.11, p.5760, 2003. 
BAIRY, K.L.; RAO, C.M. Wound healing profile of Ginko biloba. J. Nat. Remedies, v.1, p.25-27, 2001.

CHUNG, L.Y. The antioxidant properties of garlic compounds: allyl cysteine, alliin, allicin, and allyl disulfide. $J$. Med. Food, v.9, p.205-213, 2006.

DEMLING, R.H.; LESLIE, D. Protein-energy malnutrition and the nonhealing cutaneous wound. Education Collaborative/ Medscape Online Clinical Module. Available at: $<$ http:// www. medscape. com/viewprogram/714_pnt $>$. Accessed on: Nov. 14, 2003.

EJAZ, S.; CHEKAROVA, I.; CH, J.W.; LEE, S.Y.; ASHRAF, S.; LIM, C.W. Effect of aged garlic extract on wound healing: a new frontier in wound management. Drug Chem. Toxicol., v.32, n.3, p.191-203, 2009.

FA R A H P O U R, M . R .; M I R Z A K H A N I, N . ; DOOSTMOHAMMADI, J., EBRAHIMZADEH, M. Hydroethanolic Pistacia atlantica hulls extract improved wound healing process; evidence for mast cells infiltration, angiogenesis and RNA stability. Int. J. Surg., v.4, p.1-11, 2015.

GUO, S.; DIPIETRO, L.A. Factors affecting wound healing. $J$. Dent. Res., v.89, n.3, p.219-229, 2010.

HEMMATI, A.A.; MOHAMMADIAN, F. An investigation into the effect of mucilage of quince seeds on wound healing in rabbit. J. Herbs Spices Med. Plants, n.7, p.41-46, 2000.

KUMAR, R.; KATOCH, S.S.; SHARMA, S. $\beta$-Adrenoceptor agonist treatment reverses denervation atrophy with augmentation of collagen proliferation in denervated mice gastrocnemius muscle. Indian J. Exp. Biol., v.44, n.5, p.371376, 2006.

LODHI, S.; SINGHAI, A.K. Wound healing effect of flavonoid rich fraction and luteolin isolated from Martyniaannua Linn. onstreptozotocin induced diabetic rats. Asian Pac. J. Tropic. Med., n.6, p.253-259, 2013.

MACDONALD, J.A.; MARCHAND, M.E.; LANGLER, R.F. Improving upon the in vitro biological activity of antithrombotic disulfides. Blood Coagul. Fibrinolysis, n.15, p.447-450, 2004.

MANCINI, R.E. Histochemical study of glycogen in tissues. Anat. Rec., v.101, n.2, p.149-159, 1948.
MARTIN, P. Wound healing-aiming for perfect skin regeneration. Science, v.276, n.5309, p.75-81, 1997.

MASHREGHI, M.; BAZAZ, M.R.; SHAHRI, N.M.; ASOODEH, A.; MASHREGHI, M.; RASOULI, M.B.; GOLMOHAMMADZADEH, S. Topical effects of frog "Rana ridibunda" skin secretions on wound healing and reduction of wound microbial load. J. Ethnopharmacol., v.145, n.3, p.793-797, 2013.

PRICHOA, F.C.; ROMAN, S.S.; MANFREDINI, V. Tissue injuries of wistar rats treated with hydroalcoholic extract of Sonchus oleraceus L. Braz. J. Med. Biol. Res., v.47, n.3, p.605-613, 2011.

RAO, K.N.; BROWN, M.A. Mast cells. Ann. N. Y. Acad. Sci., v.1143 n.1, p.83-104, 2008.

RASIK, A.M.; SHUKLA, A. Antioxidant status in delayed healing type of wounds. Int. J. Exp. Pathol., v.81, n.4, p.257-263, 2000.

SAEED, N.; KHAN, M.R.; SHABBIR, M. Antioxidant activity, total phenolic and total flavonoid contents of whole plant extracts Torilis leptophylla L. BMC Complement. Altern. Med., v.12, n.1, p.221, 2012.

SHEEHAN, D.C.; HRAPCHAK, B.B. Theory and practice of histotechnology. St. Louis: C.V. Mosby, 1980. p.159-179.

SHIN, J.H.; RYU, J.H.; KANG, M.J.; HWANG, C.R.; HAN, C.R.; KANG, D. Short-term heating reduces the antiinflammatory effects of fresh raw garlic extracts on the LPS-induced production of NO and pro-inflammatory cytokines by downregulating allicin activity in RAW 264.7 macrophages. Food Chem. Toxicol., n.58, p.545-551, 2013.

SUNDARESAN, S.; SUBRAMANIAN, P. Garlic modulates lipid peroxidation and antioxidant status during $\mathrm{N}$-Nitrosoethylamine-induced hepatic tumorigenesis. Plant Foods Hum. Nutr., n.58, n.3, p.1-8, 2003.

SÜNTAR, I.; TUMEN, I.; USTUN, O.; KELES, H.; AKKOL, E.K. Appraisal on the wound healing and anti-inflammatory activities of the essential oils obtained from the cones and needles of Pinus species by in vivo and in vitro experimental models. J. Ethnopharmacol., v.139, n.2, p.533-540, 2012. 
THE OHARIDES, T.C.; A N GELIDOU, N.A.; ALYSANDRATOS, K.D.; ZHANG, B.; ASADI, S.; FRANCIS, K.; KALOGEROMITORS, D. Mast cell activation and autism. Biochim. Biophys. Acta (BBA)-Mol. Basis. Dis., v.1822, n.1, p.34-41, 2012.

TOOLE, B.P.; WIGHT, T.N.; TAMMI, M.I. Hyaluronan-cell interactions in cancer and vascular disease. J. Biol. Chem., v.277, n.7, p.4593-4596, 2002.

TURLEY, E.A.; NOBLE, P.W.; BOURGUIGNON, W.L.Y. Signaling properties of hyaluronan receptors. J. Biol. Chem., v.277, n.7, p.4589-4592, 2002.

WALKER, H.L.; MASON Jr., A.D. A standard animal burn. J. Trauma, v.8, n.6, p.1049-1051, 1968.
WOLFE, R.R.; GOODENOUGH, R.D.; BURKE, J.F.; WOLFE, M.H. Response of protein and urea kinetics in burn patients to different levels of protein intake. Ann. Surg., v.197, p.163-171, 1983.

YOUNAN, G.J.; HEIT, Y.I.; DASTOURI, P.; KEKHIA, H.; XING, W.; GURISH, M.F.; Orgill, D.P. Mast cells are required in the proliferation and remodeling phases of microdeformational wound therapy. Plast. Reconstr. Surg., v.128, n.6, p.649-658, 2011.

ZIMMERMANN, M. Ethical guidelines for investigations of experimental pain in conscious animals. Pain, v.16, n.2, p.109-110, 1983.

Received for publication on $12^{\text {nd }}$ April 2015 Accepted for publication on $10^{\text {th }}$ August 2016 